\title{
Developing Physical Activity Interventions for the School and Home Settings: Lessons Learned from a Community-Academic Partnership
}

\section{Zachary Ramsey}

West Virginia University Health Sciences Center

Karen Northrup

Wood County Schools

Charlotte Workman

West Virginia University Health Sciences Center

Traci Jarrett

West Virginia University Health Sciences Center

Nancy O'Hara Tompkins

West Virginia University Health Sciences Center

Lesley Cottrell ( $\square$ lcottrell@hsc.wvu.edu )

West Virginia University Health Sciences Center

\section{Research}

Keywords: physical activity programming, rural setting, public health workforce, school and home settings

Posted Date: June 8th, 2020

DOl: https://doi.org/10.21203/rs.3.rs-32129/v1

License: (c) (i) This work is licensed under a Creative Commons Attribution 4.0 International License. Read Full License 


\section{Abstract \\ Background}

Physical activity interventions designed for children living in the rural setting, particularly those that are cost effective and utilize common resources, are increasingly requested. Interventions for school and home settings are available but can be complicated and expensive to deliver.

\section{Methods}

In this study, we developed two physical activity interventions to be implemented in the school and home environments within rural settings of varying sizes and resources. This study, Activate!, was based on the socioecological model (SEM) and informed by local school personnel, families, and community health workers. Community members contributed to the development and implementation of the program.

\section{Results}

The resulting intervention package included several resources that were either already available in the school or home settings or could be easily collected by facilitators. Recommendations for frequency of use, capturing whether it is working, and methods for encouraging children and families were included in the packaging.

\section{Conclusions}

In this project, we successfully incorporated community (school and home) needs from a largely rural state within Appalachia to develop physical activity interventions for children. The Activate! interventions were designed for easy implementation by community members directly in both the school and home environments using common materials and easily reviewed packaging and guidance.

\section{Background}

Physical activity (PA), according to the 2018 Physical Activity Guidelines for Americans, is "any bodily movement produced by the contraction of skeletal muscle that increases energy expenditure above the basal level... or generally... to bodily movement that enhances health" ${ }^{1}$ National recommendations encourage children (5-12 years) to engage in at least 60 minutes of physical activity daily. ${ }^{2}$ To date, national surveillance reports of children (6-17 years) in 2017-2018 illustrate that $9.5 \%$ of children do not engage in physical activity and that slightly less than $40 \%$ only engage in 1 to 3 days of activity. ${ }^{3}$

Researchers and public health professionals developed children's physical activity interventions with increasing accessibility, ${ }^{4-6}$ particularly for children with varying abilities. ${ }^{6-8}$ These efforts produced several 
comprehensive programs (physical activity + nutrition) for children that increase physical activity in the short-term as well as long-term health outcomes. ${ }^{9-11}$ Once established, these programs were implemented in a variety of settings to test their generalizability. ${ }^{12-14}$ Challenges include cost, demands from host resources (staff, space), and confusion about how other partners could be involved to expand the impact of the interventions. ${ }^{15}$ Additional needs of educators and families including the need to think outside of the physical education curriculum and connect a child's school experiences with home life have been identified since these programs were developed. For instance, the Comprehensive School Physical Activity Program (CSPAP), which promotes a "whole school, whole community, whole child" model, notes the multiple opportunities to intervene in a child's activity. ${ }^{16}$ Thus, there was an opportunity to use the prior research experience as a foundation to build programming specific to homes and school districts that have little resources but great public health concerns.

The proposed interventions were designed to address four significant research gaps in West Virginia $(\mathrm{WV}): 1$ ) is there added benefit to incorporating scheduled activity breaks into the classroom on children's PA, health, and academics? 2) what value is added to children's PA by parent-based efforts within home and neighborhood settings? 3) does the impact from the school- and family-based strategies differ based on certain school and community demographics? and 4) what are the cost estimates and economic benefits of these strategies? The interventions were designed to require little resources in both the school and home settings, and to be easily integrated into existing school and home schedules and activities. The long-term goal of the interventions was similar to established programs - to increase student PA, improve aerobic fitness, combat health risks, and improve academic performance using a coordinated schools approach that incorporates school and family-based strategies that promote physical activity. Once developed, the Activate! interventions were tested using a randomized controlled trial (RCT). The purpose of this manuscript is to describe the process, partners, and challenges experienced in the design of the Activate! interventions and to review the lessons learned from the intervention development and implementation processes.

\section{Methods}

\section{Theoretical Framework}

The socioecological model (SEM) ${ }^{17}$ was chosen as the theoretical basis for the interventions for several reasons. First, the SEM conceptualizes an individual's behavior as being influenced by many factors in surrounding home, school, neighborhood, and larger political, cultural systems. Secondly, it considers the influence of the interaction across characteristics of the individual and those found within the environmental systems. The SEM also theorizes that individuals can influence factors in the surrounding systems. Thus, interventions or changes in individuals' characteristics or behaviors could possibly influence those of parents, peers, and even policy based on the nature of the situation. Finally, the model considers how time might modify the interaction between the individual and his/her environment as development and experiences advance. Activate! intervention components, once developed, were mapped 
to the constructs found within the SEM. Specifically, lessons and activities were developmentally based on the specific age group enrolled in the study (10 to12-year-olds). Both the school and home interventions incorporated ways in which individuals from the surrounding environments, particularly parents and adults in the home, siblings, classroom teachers, and peers in the classroom, might influence the participating student's physical activity behavior (e.g., role modeling, goal setting).

\section{Project Identity and Community Partnership}

The research project was proposed for nine counties within the Mid-Ohio Valley region of West Virginia (WV). This region was chosen given its representation of the heterogeneous neighborhoods and school infrastructures found within Appalachia. The research team previously worked with some of the local schools to better understand the relationship between physical activity and academics. ${ }^{18-20}$ It was important to us to establish a research process that involved our community partners, particularly representatives from the schools, families, and community organizations including the local health department. In our experiences, increased community involvement was associated with increased ownership of the program and sustainability of activities once implemented.

During the first year, the research team worked with local elementary schools (not in the study region) to determine a project name. Three schools with $5^{\text {th }}$ grades participated in a poster contest about physical activity. Out of 123 entries, one was selected as the winner (see Figure 1) and received a new bicycle as a prize. Second and third place entrants were awarded scooters. A combination of several posters contributed to the development of the Activate! mascot, Brainy, that connected brain activity with physical activity (see Figure 2). Brainy and the Activate! name were then used to create incentives and project materials for participants.

\section{Design}

Two independent interventions - one for the school setting and one for the home setting - were originally conceptualized and later developed based on the SEM and contextual resources. These interventions were compared to a control group, which included standard practices in both settings. The cross-section design included three cohorts of student-parent dyads and school personnel (one cohort per academic year). Schools were randomized to receive one of the three arms in the study. Schools required superintendent and principal approval. Enrolled participants would provide a baseline, mid-year, and final assessment (end of year). An additional survey would be later collected at the one-year anniversary.

A Research to Policy (R2P) Council was established composed of 15 members including school administration, teachers, parents, and policy makers throughout the state. The role of the R2P was to work closely with the investigators on the design, implementation, and data collection process aligning these efforts closely with other initiatives targeting improved physical activity among children and their families. The hypothesized role of this group was to identify and align the study activities with opportunities to translate findings into policy and practice changes. 


\section{School Intervention}

A menu of physical activities designed for fifth grade classroom teachers was created for the school intervention arm of the Activate! research study. The research team reviewed approximately 25 classroom-based physical activity programs, resources, and websites for potential inclusion in the Activate! menu of strategies. Review criteria included evidence of effectiveness, cost (low or no cost resources were prioritized for inclusion), experience/expertise of the design team, and ease of implementation. Other criteria included strategies that allowed for involvement of all students and consideration of the four spaces of the classroom (corner, row, self-space, projection). Rather than using one particular resource, activity cards were created by intervention personnel with teaching backgrounds who explored the resources and selected and adapted non-copyrighted activities that would be most practical given the commonplace equipment and space of the average classroom. The training package was intentionally developed with consideration of user (teacher) needs and with translation (use by others) in mind. Avoiding characteristics that can limit the likelihood of use and translation to other audiences, e.g., high-cost, time-intensive, difficult to learn, unpackaged and not customizable, was a paramount consideration.

The resulting intervention package included several resources: 1) activity cards created and categorized into Brain Boosters (short bursts of physical activity/movement typically used during lesson transitions) and Integrated Physical Activity activities (physical activity/movement purposefully integrated into an academic lesson to enhance/reinforce learning); 2) an Activate! toolkit (valued at $\sim \$ 100 /$ kit) containing equipment and supplies for teachers to implement the card activities and a listing of links to free/lowcost web-based resources (see Table 1), and 3) a one-day professional development opportunity, and 4) monthly e-mails from the trainer for persistent support and encouragement.

Fifth grade classroom teachers and elementary level physical education (PE) teachers attended a one-day training in the fall of the school year. PE teachers were explicitly invited because of their potential role as physical activity leaders or champions in their schools. ${ }^{21}$ Teachers participated in a variety of interactive activities in which they practiced using the materials/equipment.

\section{Family Intervention}

The local health department empowered existing community health workers (CHWs) to coordinate activities with participating families randomized to the family group. This approach has been previously tested and shown to promote healthy behaviors among children, particularly in isolated communities on a national level. ${ }^{22}$ The CHW, AmeriCorps members from the Mid-Ohio Valley Health Department (MOVHD), served as the family's mentor throughout the academic year and maintained communication with the families to check on their progress over time.

An eight-month curriculum was delivered with the goal of incorporating family-based activities to increase physical activity over time. Each month's physical activity theme included a set of materials (e.g., educational handout, checklists, and activity sheets) and a family-based action plan that was developed 
and followed throughout the program period (see Table 2). Delivery of the intervention began with a home visit. A CHW reviewed materials with the enrolled child and at least one parent at baseline and worked with the family to: 1) develop a physical activity action plan, and 2) complete a home physical activity environment checklist to see what resources were already available within the home setting for physical activity that would be applicable for the student. After the initial visit, the $\mathrm{CHW}$ communicated with the family by mailing them the monthly materials and calling them to check on their progress for the family action plan. Interactions with the families were documented in a RedCAP data base system. ${ }^{23}$

Once each family developed an initial action plan, they chose equipment from a list of physical activity options (e.g., resistance bands, snow play toys, small hand weights) estimated cost of $\$ 50$ that was incorporated into their plan to increase activity as a family. The student and participating parent were also given a Fitbit to objectively assess their physical activity. These allowed students to engage in physical activity challenges each month and receive feedback on the amount of physical activity they were accumulating.

The family intervention incorporated two opportunities for families based on additional resources they had or were interested in trying. These were in addition to the core components (home visits/monthly activity themes/action planning). The first opportunity, CHW's sponsored Family Fun Nights (FFNs), related to the physical activity theme for that month. The FFNs were coordinated and led by MOVHD staff and included a sign in sheet, healthy snack options, demonstrated physical activities, and themed materials related to physical activity for the whole family. The FFNs were conducted at local schools or community buildings. The second opportunity incorporated targeted social media messaging to participating parents via a closed Facebook group. These messages served to educate and motivate the family participants. General messaging was aligned with the intervention curriculum and sought to reinforce consistent intervention messaging. Targeted messaging was tailored to each parent-child stage of PA behavior change.

\section{Incorporating SEM Into Interventions}

The SEM's organization and conceptualization of children's behavior and factors influencing that behavior were important to the development of the Activate! interventions. Attention was given to individual settings/levels but also to the interaction between the child and parent/teacher or across children and parents. Figure 3 maps SEM constructs with Activate! activities and processes to illustrate how the SEM supported the structure of the Activate! interventions.

The activity lessons incorporated within Activate! also focused on the potential influence on, and from, children rather than always emphasizing the influence on the child from an adult provider. This intentional inclusion provided an opportunity for the Activate! materials to empower the children and to teach adults how to empower children to become change agents themselves. Developmental messages for all age groups within the family (multi-generational content) were also available for each theme and within the curricula for the family intervention (see Table 3). 


\section{Incorporating Community Expertise}

Community involvement in the project development phase was key and was initially defined by establishing a collaborative relationship with the local health department. Historically, the local health department (MOVHD) offers many community programs targeting health outcomes and reaching families within the region. This mirrored the nature of the Activate! project plans. Early partner meetings quickly identified the opportunity to utilize a community health worker model ${ }^{24}$ that had been implemented in the health department to disseminate a blood pressure and diabetes programming. Community Health Workers (CHWs) were recruited from the AmeriCorps program initially. Those with interests in pediatric and/or physical activity programming and who had previously experience with family-focused interventions were considered and later supported (partial or full effort) through the Activate! funding.

As noted earlier, the CHWs were the program's connection to the community and families who would later be involved in the family intervention portion of the Activate! project. Thus, they were primarily responsible for implementing the family intervention throughout the proposed seven-county region. However, additional responsibilities including community training, meeting logistics, and training focused on the particular Activate! study family intervention monthly offerings.

We also engaged physical activity specialists at the local and state levels throughout the project. Two retired physical activity specialists were hired to develop the school intervention, conduct the teacher training and provide ongoing implementation-related email communication with the trained teachers. These specialists worked closely with the investigative team and provided key insights about how school systems work. Furthermore, we partnered with the physical activity specialist at the State Department of Education to ensure that our strategies aligned with what was occurring statewide. This poised us to be ready for translation of findings into recommendations for policy and practice changes.

Select data collection procedures were seen as important training opportunities for both the CHWs and the physical activity specialists as well as opportunities for the entire team to work with one another on aspects of the research project involving all study conditions. For instance, $\mathrm{CHW}$ and physical activity specialists' involvement in the data collection procedures provided an opportunity for them to contribute to discussions about quality improvement, assurance, and implications of the collected data. Additionally, the CHWs would be able to interact with physical activity specialists regarding communityschool collaborations such as Family Fun Nights and future programming that would combine these settings even more. All CHWs and physical activity specialists were trained in research ethics.

\section{Lessons Learned}

Conceptual Complexities. Incorporating the SEM framework into the Activate! interventions allowed us to build strategies that focused on the individual student's behavior as well as possible influencers from environments with which they interact on a daily basis. While this model allowed us to examine students' physical activity changes over time using a non-static concept, it introduced a complex analytic model. 
Truly mapping a measurement model to the SEM can be complicated, confusing, and require very large sample size. While we defined a sample size that would be adequate to test the full SEM model, we also developed an analytic approach that looked at different relationships throughout the model in separate analyses. In other words, we developed a way in which we could capture the dynamic, potentially bidirectional, relationships among model variables but doing so in separate snapshots rather than one large analytic model. The SEM has been incorporated into physical activity approaches previously. ${ }^{25-27}$ Langille and Rodgers ${ }^{26}$ similarly focused on physical activity within the school setting incorporating multiple levels of influence within that setting. Their findings illustrated a "trickled down" approach in responsibility to organize physical activity for students as a result. Bauman and colleagues were also able to illustrate interactions across multiple sectors including the health sector and genetic factors contributing to one's likelihood of engaging in physical activity. ${ }^{27}$

Onboarding Program Sites and Consent. Recruitment into the Activate! study started the county level. Once a school agreed to be a participating site, we randomized it to one of the three conditions (standard practices, school intervention, family intervention), and eligible students within the school could receive appropriate consent materials and information. Obtaining superintendent consent was challenging given timelines; however, the team was successfully able to present study fundamentals to consolidated groups of superintendents during the summer months later in the timeline. Providing this information and sample support letters were impactful on timeline and understanding later in the study. A similar approach was used at the individual school level with principals and teachers. These presentations also appeared to help with family recruitment. Principal and teacher knowledge of the study and ability to respond to questions parents may have provided a significant benefit.

Organization of Community Activities. Early in the project, the team provided initial layouts of the monthly themes for the family intervention. These served as the plan for the remaining portion of the school year. However, much of the instruction was provided on paper and not reviewed prior to the select activities (Family Fun Nights). As a result, teams were often confused about the sequence or fundamental message intended from the event, leaving the potential for families to not understand the true intention and messages for that activity. Once identified, the team moved to a model where reviews of the themes and each activity (materials needed, preparation required, process review, message) were held the month prior to consolidate the team's approach, discuss challenges that had occurred in the previous month, identify solutions to those challenges, and clarify any confusion about the intent of the activity. This modification increased cohesion among team members and consistency in the delivery of the materials.

Distributing School Cohorts Based on Readiness. As noted earlier, each school site was randomized to receive one of three conditions. This process was originally developed by the team biostatistician but we experienced challenges after some schools were not able to provide consent in time if randomized to the first cohort. While this did not happen in most cases, we reconfigured the randomization so that schools would be able to choose which cohort (not study condition) they wanted based on their readiness to begin teacher training. Several schools chose to start with cohort 1 (Year 2 of the study) leaving unequal amounts of schools for the remaining two cohorts. Fortunately, this was not an issue for the treatment 
randomization. Study conditions were equivalent in terms of the number of schools, school personnel participating, and student-parent dyads. Our study team discussed the issue of randomization and potential confounds annually so that if issues arose, we would be able to address them. The R2P also participated in those discussions to ensure that any changes would also be in line with any translational activities planned later in the study timeline (e.g., communication plan with schools, community groups, and family groups).

Using Innovative Tools in Research. Particularly for rural settings, researchers seek to find tools and methods that allow them to reach participants where they live and work rather than limit their interactions to scheduling a time to come together. Some of the tools in the Activate! study were specifically identified with the hope they would provide information from the participants to the team without requiring participants to be in one place each time. For instance, physical activity tracking devices were chosen that were secure, easily worn by participants, and would work within the network of the rural setting. While these tools provided this opportunity to the team, additional challenges were addressed related to the innovative use in a new setting. These challenges included the need to train individuals on how to use a new device/tool, offering reminders for wearing the device daily or during the specified period of time, and developing procedures for what to do if a device broke or was lost. The team developed helpful materials for families and conducted routine trainings on these areas to reduce data loss, connect participants to other participants to maximize potential impact of the device (using challenges on the tracker to compete with other participants).

\section{Conclusions}

In this project, we successfully incorporated community (school and home) needs from a largely rural state within Appalachia to develop physical activity interventions for children. The Activate! interventions were designed for easy implementation by community members directly in both the school and home environments using common materials and easily reviewed packaging and guidance. These intervention materials were theoretically-based on the SEM, evidence-based physical activities, and tools proven to be effective with children by teachers and families in these settings. While we faced some challenges, we were able to incorporate a complex theory and potentially costly intervention options into a design that could be implemented easily into busy family and school schedules. Along the way, we learned ways to incorporate a research design or new intervention more efficiently, increase stakeholder buy-in, and clearly communicate the purpose and potential significance of this program for schools and families in our area. These lessons are applicable to others who want to either tailor existing programming or develop new options that fit the lifestyle, values, and economy of their area to improve their children's physical activity.

\section{Declarations}

Ethics approval and consent to participate. All activities were reviewed and approved by the West Virginia University Institutional Review Board. Human subjects were consented following ethics approval. 
Consent for publication. Consent included data collection and use of information for publication.

Availability of data and material. The datasets used and/or analyzed during the current study are available from the corresponding author on reasonable request.

Competing interests. Authors do not have any financial or non-financial competing interests to disclose at this time.

Funding. This study was funded by the Centers for Disease Control and Prevention (I-U48-DP-005004).

Authors' contributions. All authors contributed to the study in a variety of ways including study conceptualization (LC, NOT), study coordination (CW, TJ, KN), data collection activities (ZR, KN, CW, TJ, NOT, LC), analyses (ZR, CW, NOT, LC), interpretation (ZR, KN, CW, TJ, NOT, LC), and manuscript development and editing (ZR, KN, CW, TJ, NOT, LC).

Acknowledgements. We would like to acknowledge the hard work and passion of our Activate! team and the children and families who participated in this study.

\section{References}

1 U.S. Department of Health and Human Services. (2018). Physical Activity Guidelines for Americans, 2nd edition. Washington, DC.

22018 Physical Activity Guidelines Advisory Committee. 2018 Physical Activity Guidelines Advisory Committee Scientific Report. Washington, DC: US Department of Health and Human Services; 2018.

3 Data Resource Center for Child \& Adolescent Health. NSCH Interactive Data Query (2016-2018). Accessed at: https://www.childhealthdata.org/browse/survey/results?q=6854\&r=1 on February 21, 2020.

4 Singh, A.S., Saliasi, E., Van Den Berg, V., Uijtdewilligen, L., De Groot, R.H., Jolles, J., Andersen, L.B., Bailey, R., Chang, Y.K., Diamond, A. and Ericsson, I., 2019. Effects of physical activity interventions on cognitive and academic performance in children and adolescents: a novel combination of a systematic review and recommendations from an expert panel. Br J Sports Med, 53(10), pp.640-647.

5 Rhodes, R.E., Blanchard, C.M., Quinlan, A., Naylor, P.J. and Warburton, D.E., 2019. Family physical activity planning and child physical activity outcomes: A randomized trial. American journal of preventive medicine, 57(2), pp.135-144.

6 Reis, R.S., Salvo, D., Ogilvie, D., Lambert, E.V., Goenka, S., Brownson, R.C. and Lancet Physical Activity Series 2 Executive Committee, 2016. Scaling up physical activity interventions worldwide: stepping up to larger and smarter approaches to get people moving. The lancet, 388(10051), pp.1337-1348.

7 Thomas, S., Hinkley, T., Barnett, L.M., May, T. and Rinehart, N., 2019. Young children with ASD participate in the same level of physical activity as children without ASD: Implications for early intervention to 
maintain good health. Journal of autism and developmental disorders, 49(8), pp.3278-3289.

8 Miller, J.M., Pereira, M.A., Wolfson, J., Laska, M.N., Nelson, T.F. and Neumark-Sztainer, D., 2019. Are Correlates of Physical Activity in Adolescents Similar Across Ethnicity/Race and Sex: Implications for Interventions. Journal of Physical Activity and Health, 1(aop), pp.1-12.

9 Whooten, R., Kerem, L. and Stanley, T., 2019. Physical activity in adolescents and children and relationship to metabolic health. Current Opinion in Endocrinology, Diabetes and Obesity, 26(1), pp.25-31.

10 Hnatiuk, J.A., Brown, H.E., Downing, K.L., Hinkley, T., Salmon, J. and Hesketh, K.D., 2019. Interventions to increase physical activity in children $0-5$ years old: a systematic review, meta-analysis and realist synthesis. Obesity reviews, 20(1), pp.75-87.

11 Langford, R., Jago, R., White, J., Moore, L., Papadaki, A., Hollingworth, W., Metcalfe, C., Ward, D., Campbell, R., Wells, S. and Kipping, R., 2019. A physical activity, nutrition and oral health intervention in nursery settings: process evaluation of the NAP SACC UK feasibility cluster RCT. BMC public health, 19(1), p.865.

12Cairney, J., Veldhuizen, S., Rodriguez, M.C., King-Dowling, S., Kwan, M.Y., Wade, T., Price, D., Missiuna, C. and Timmons, B., 2019. Cohort profile: the Canadian coordination and activity tracking in children (CATCH) longitudinal cohort. BMJ open, 9(9), p.e029784.

13 Beets, M.W., Weaver, R.G., Ioannidis, J.P., Geraci, M., Brazendale, K., Decker, L., Okely, A.D., Lubans, D., Van Sluijs, E., Jago, R. and Turner-McGrievy, G., 2020. Identification and evaluation of risk of generalizability biases in pilot versus efficacy/effectiveness trials: a systematic review and metaanalysis. International Journal of Behavioral Nutrition and Physical Activity, 17(1), p.19.

14 Lee, R.M., Barrett, J.L., Daly, J.G., Mozaffarian, R.S., Giles, C.M., Cradock, A.L. and Gortmaker, S.L., 2019. Assessing the effectiveness of training models for national scale-up of an evidence-based nutrition and physical activity intervention: a group randomized trial. BMC public health, 19(1), p.1587.

15 Cassar, S., Salmon, J., Timperio, A., Naylor, P.J., van Nassau, F., Ayala, A.M.C. and Koorts, H., 2019. Adoption, implementation and sustainability of school-based physical activity and sedentary behaviour interventions in real-world settings: a systematic review. International Journal of Behavioral Nutrition and Physical Activity, 16(1), p.120.

16 Society of Health and Physical Educators. Comprehensive school physical activity program (CSPAP). Accessed at : https://www.shapeamerica.org/cspap/what.aspx on March 25, 2020.

17 Bronfenbrenner U, Morris PA. Handbook of child psychology, 2007.

18 Wittberg, R.A., Northrup, K.L. and Cottrell, L.A., 2012. Children's aerobic fitness and academic achievement: a longitudinal examination of students during their fifth and seventh grade years. American journal of public health, 102(12), pp.2303-2307. 
19 Cottrell, L.A., Northrup, K. and Wittberg, R., 2007. The extended relationship between child cardiovascular risks and academic performance measures. Obesity, 15(12), pp.3170-3177.

20 Northrup, K.L., Cottrell, L.A. and Wittberg, R.A., 2008. LIFE: A school-based heart-health screening and intervention program. The Journal of School Nursing, 24(1), pp.28-35.

21 O’Hara Tompkins, N., Weikle, M., Keath, A., Northrup, K., Childers, S., Grant, J., Sirk, H., \& Wittberg, Richard. Professional development for increased classroom-based physical activity: Elements and strategies to reduce barriers and facilitate implementation. Journal of Health, Physical Education, Recreation \& Dance 90:9, 38-52, 2019.

22 Singh P, Chokshi DA. Community health workers - a local solution to a global problem. N Engl J Med. 2013;369(10):894-6.

23 PA Harris, R Taylor, BL Minor, V Elliott, M Fernandez, L O’Neal, L McLeod, G Delacqua, F Delacqua, J Kirby, SN Duda, REDCap Consortium, The REDCap consortium: Building an international community of software partners, J Biomed Inform. 2019 May.

24 Corporation for National and Community Service. Americorps. Accessed at: https://www.nationalservice.gov/programs/americorps on March 10, 2020.

25 Carson RL, Castelli DM, Beighle A, Erwin H. School-pbased physical activity promotion: A conceptual framework for research and practice. 2014; Childhood Obesity; 10(2): Review.

26Langille JLD, Rodgers WM. Exploring the influence of a social ecological model on school-based activity. 2010. Health Educaiton \& Behavior; 37(6): 879-894.

27Bauman AE, Reise RS, Sallis JF, Wells JC, Loos RJF, Martin BW. Correlates of physical activity: Why are some people physically active and others not? 2012. The Lancet; 380 (9838): 258-271.

\section{Figures}


Figure 1. Winning School Poster

GETUP, GET OUT, GETEH

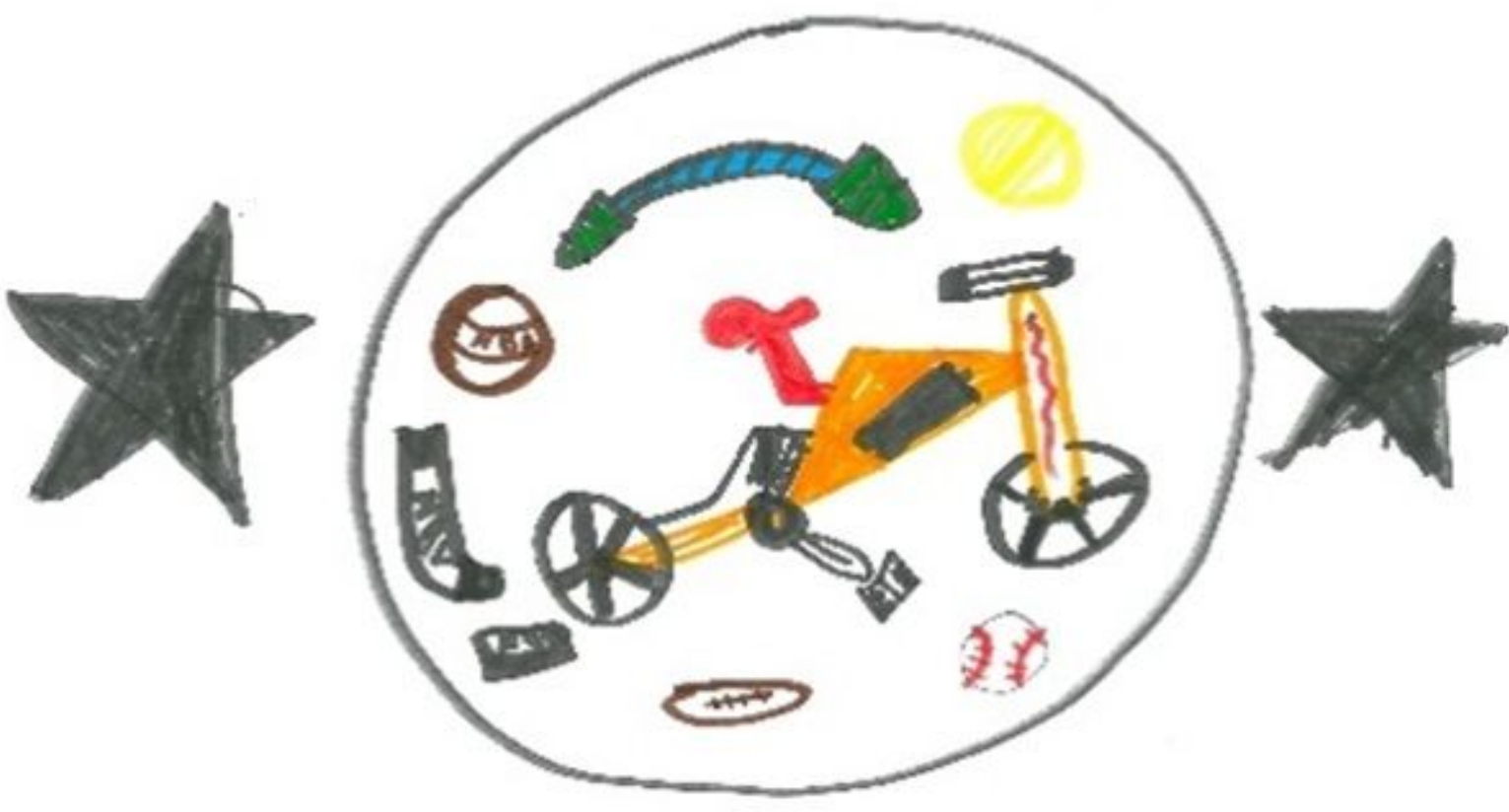

Figure 1

Winning School Poster 
Figure 2. Project Logo

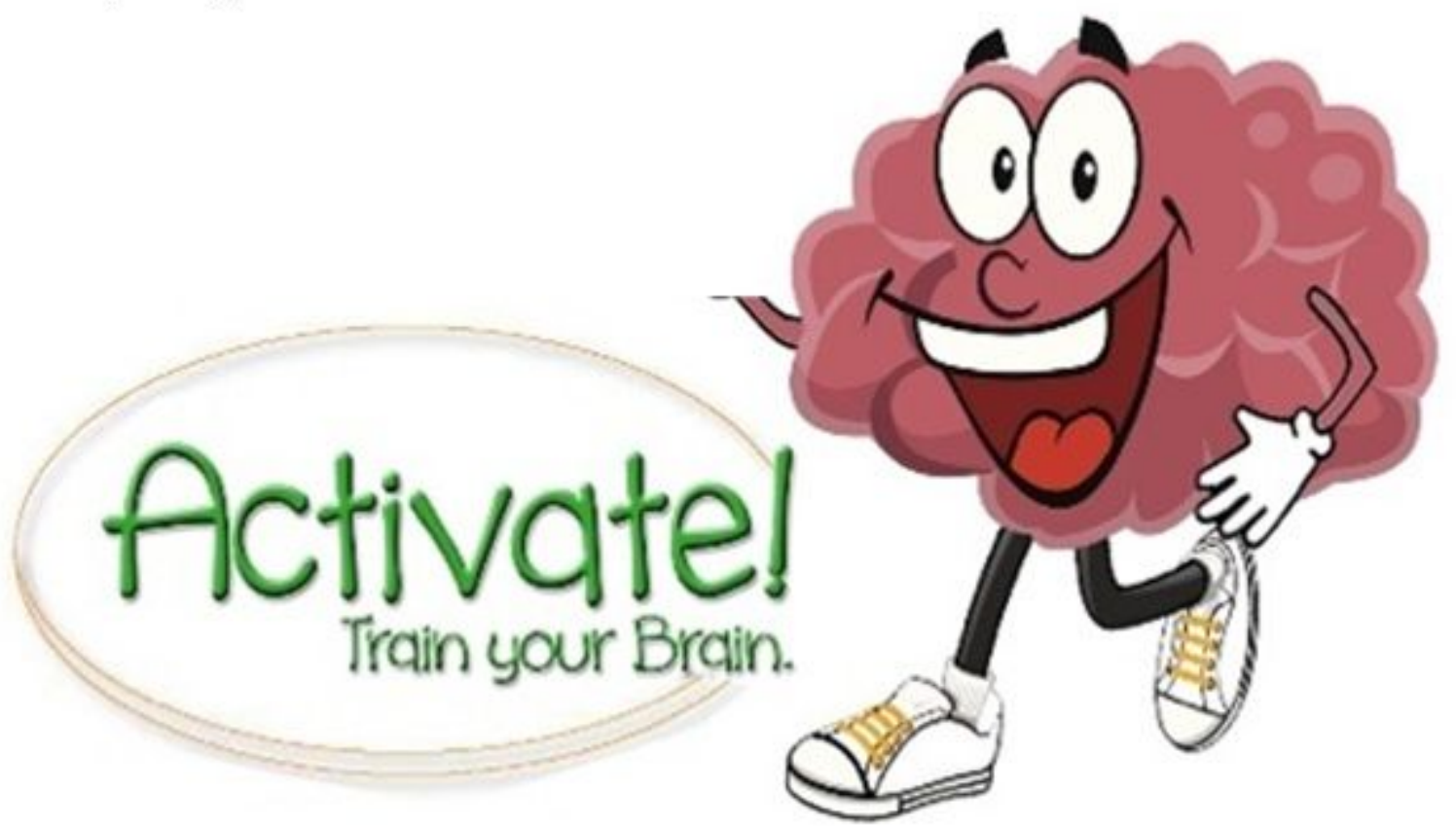

Figure 2

Project Logo

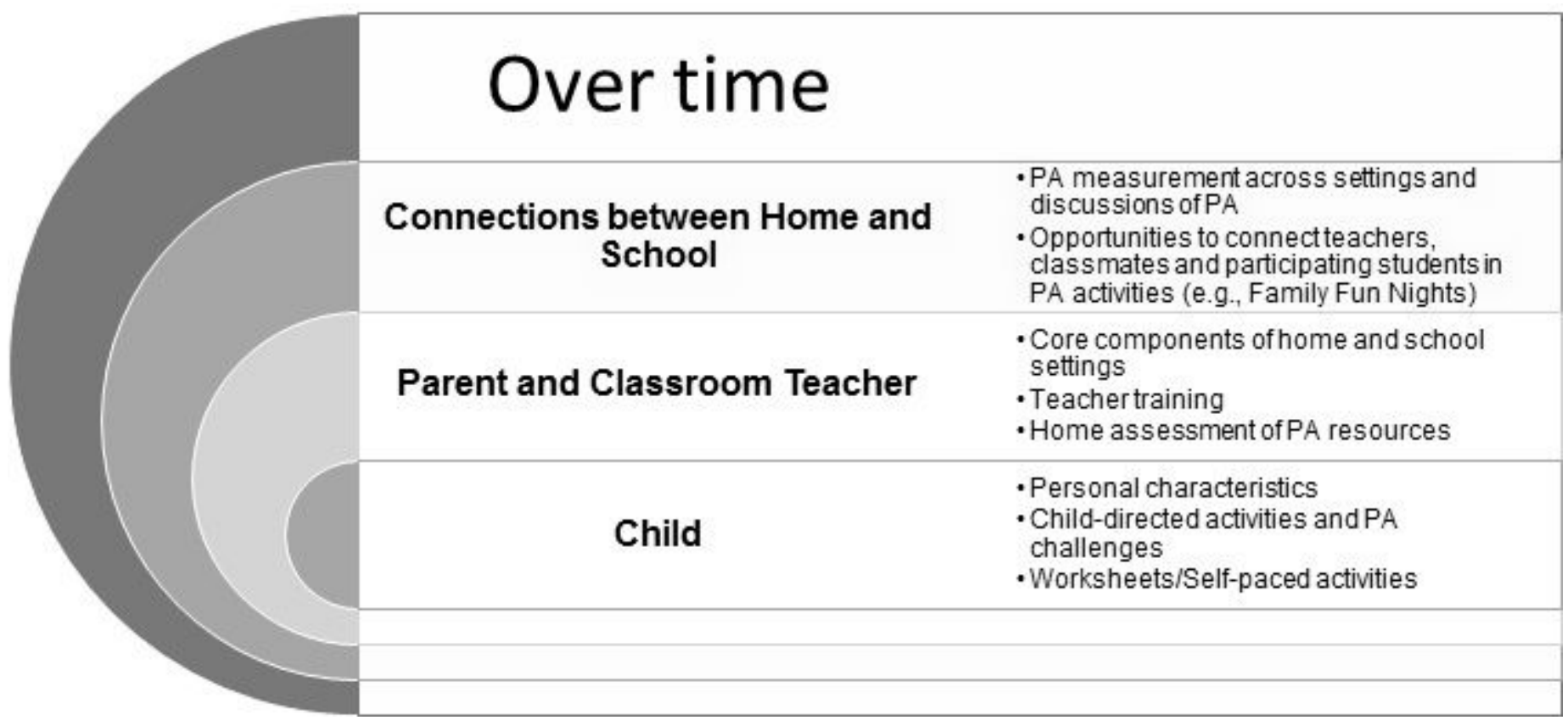

Figure 3

SEM Constructs Mapped to Activate! Intervention Elements 